\title{
THE CAUSE OF REDUCTION OF THE SUGAR CONTENT OF THE CEREBROSPINAL FLUID IN MENINGITIS
}

\author{
BY \\ ESTHER HENDRY, M.B., Ch.B.
}

(From the Department of Paediatrics, Glasgow University, and the Biochemical Laboratory, Royal Hospital for Sick Children, Glasgow)

Reduction in the glucose content of the cerebrospinal fluid is a familiar finding in all forms of meningitis, but the cause of this has not yet been definitely determined. In a previous communication (1939) it was shown that it not due to diminution in blood sugar content, and it appears that the phenomenon must be due either to too little sugar entering the cerebrospinal system on account of pathological changes in the blood-brain barrier or to glycolysis within the fluid itself.

The work of Dandy (1919) and Weed (1914) established beyond doubt that the source of origin of the cerebrospinal fluid is the choroid plexus in each of the lateral ventricles, and, in view of the widespread changes which are known to occur in this area in meningitis, it seems reasonable to suppose that the permeability of the plexus will be affected. Tcherkassov and Jolkver (1935) believe that the plexus undergoes changes in all forms of meningitis and, as recovery takes place, normal function is restored. Weichsel and Herzger (1936) explain the diminution in cerebrospinal fluid sugar on the basis of diminished circulation of blood through the plexus with a raised threshold for sugar. In support of their views they quote the work of Walter (1929), who finds an increased passage of protein and bromides in inflammatory conditions of the meninges though the sugar threshold is above normal. Linder and Carmichael (1928), on the other hand, exclude the possibility of changes in permeability on the grounds that the reduction in the chlorides of the cerebrospinal fluid in meningitis is proportionate to the reduction in serum chlorides.

The alternative that sugar is secreted in normal amount and subsequently destroyed in the cerebrospinal fluid remains to be considered.

Kopetzy (1933) found experimentally that raised intracranial pressure, by interfering with the cerebral circulation, caused lessened oxidation in the affected area, and in conjunction with Fishberg (1933) suggested that anaerobic glycolysis takes place with excessive formation of lactic acid. It is well known that the lactic acid content of the cerebrospinal fluid in meningitis is above normal and that, owing to over-production of cerebrospinal fluid, the intracranial pressure is 
raised, but it seems unlikely that these two factors bear any relationship to one another.

Chevassut (1927) claims that there is a glycolytic ferment in normal cerebrospinal fluid, but she does not show that this is increased in meningitis, though she suggests that in pathological conditions the action of the ferment is accelerated by the presence of cells or organisms. Tcherkassov and Jolkver (1935) believe that such a ferment may be the cause of reduction in cerebrospinal fluid sugar content in meningitis, but show no experimental proof of this. Other workers, Fasold and Schmidt (1929) and Rimele (1938), are unable to detect glycolysis in normal sterile cerebrospinal fluid even after allowing it to stand for several days.

It has been suggested that the presence of bacteria or an excess of leucocytes in the cerebrospinal fluid may be the cause of this lowering of sugar in meningitis. Soedjono (1938) found that the addition of b. coli, staphylococci or pneumococci to normal cerebrospinal fluid brought about almost complete glycolysis in two to three days, while Rimele (1938) found this to be the case only on addition of $b$. coli or b. subtilis.

It is known that normal blood removed from the body and kept under sterile conditions decreases in sugar content. McLeod (1921) is of the opinion that glycolysis is brought about by the action of both red and white cells, and that suspensions of leucocytes, such as dilute pus, are strongly glycolytic. Barron and Harrop (1929) hold that the white cells of the blood have a much higher metabolic activity than the erythrocytes and that polymorphonuclears have five times the glycolytic power of lymphocytes.

Levene and Meyer (1912) were the first to test the sugar-destroying power of leucocytes in vitro. They obtained sterile polymorphic exudates by injection of 1.5 c.c. of turpentine into the pleural cavity of dogs, centrifuged the aspirated fluid, and added the resulting deposit of cells to sterile Henderson phosphate mixture to which glucose had been added. After incubation reduction in the sugar content of the supernatant fluid was found.

Investigating the action of white cells on spinal fluid, Soedjono (1938) found that in normal cerebrospinal fluid with cell counts ranging from 3 to 15 per c.mm., kept under sterile conditions from six to ninety-six hours at room temperature or $0^{\circ} \mathrm{C}$., there was no change in sugar content and no glycolysis when extra sugar was added. Cerebrospinal fluid from cases of meningitis left standing showed reduction of sugar content in six hours, in which time added glucose had also disappeared. These changes were most marked in fluids from purulent meningitis, less so in those from tuberculous cases. After adding white blood cells to normal cerebrospinal fluid, he demonstrated glycolysis which was proportional to the number of cells added. No breakdown of sugar resulted when lymphocytes were used instead of polymorphonuclear cells, a finding which supports the work of Barron and Harrop (1929).

From the foregoing review of the literature it seems unlikely that lessened permeability of the choroid plexus to the passage of sugar into the cerebrospinal fluid is the cause for the reduction in its sugar content in meningitis. The evidence points to the reduction being due to the action either of bacteria or of white blood corpuscles.

\section{Present investigation}

Tests were devised to determine in meningitis : (1) if there is alteration in the permeability of the blood-brain barrier to glucose ; (2) if the action of 
bacteria is the cause of the reduction of sugar in the cerebrospinal fluid ; or (3) if the presence of leucocytes is responsible for the reduction.

Methods. - The spinal fluid sugar was estimated by a modified Folin-Wu (1920) method using 1 c.c. of fluid. The lactic acid content of 0.5 c.c. of blood or spinal fluid was estimated colorimetrically with hydroquinone after precipitation of protein by sodium metaphosphate and sulphuric acid, and of carbohydrate by calcium hydroxide and copper sulphate.

1. Alteration in the permeability of the blood-brain barrier.-The opportunity was afforded to examine the sugar content of the cerebrospinal fluid before and after the intravenous injection of glucose in one case of cerebral diplegia and in one of miliary tuberculosis, in both of which the cerebrospinal fluid was normal. These cases served as controls. Similar tests were carried out in seven cases of tuberculous meningitis. The results are shown in table 1. From this it will be seen that in five of the seven cases of meningitis there was a relatively greater rise in the sugar content of the spinal fluid after the administration of glucose intravenously than in the two control cases. In the case of M.A.M. it is possible that insufficient allowance was made for the time lag which occurs in the reaction of the cerebrospinal fluid to the intravenous injection of glucose, as the second specimen of cerebrospinal fluid was examined only half an hour after the injection was given. In the case of $\mathrm{R}$. McN. the rise is almost as great as that found in one of the control cases.

TABLE I

TO SHOW THE INCREASE IN CEREBROSPINAL FLUID SUGAR CONTENT AFTER $\frac{1}{2}$ GM. GLUCOSE PER KGM. BODY WEIGHT GIVEN INTRAVENOUSLY

\begin{tabular}{|c|c|c|c|c|c|}
\hline \multirow{2}{*}{ NAME } & \multicolumn{3}{|c|}{ C.S.F. SUGAR, MGM. PER CENT. } & \multirow{2}{*}{$\begin{array}{c}\text { PERCENTAGE } \\
\text { INCREASE IN } \\
\text { C.S.F. SUGAR } \\
\text { CONTENT }\end{array}$} & \multirow{2}{*}{ DIAGNOSIS } \\
\hline & $\begin{array}{c}\text { BEFORE } \\
\text { INJECTION }\end{array}$ & $\begin{array}{l}\text { TIME, } \\
\text { HOURS }\end{array}$ & $\begin{array}{c}\text { AFTER } \\
\text { INJECTION }\end{array}$ & & \\
\hline $\begin{array}{l}\text { J. H. } \\
\text { G. McA. }\end{array}$ & $\begin{array}{l}60 \\
61\end{array}$ & $\begin{array}{l}1 \\
1 \frac{1}{2}\end{array}$ & $\begin{array}{l}98 \\
86\end{array}$ & $\begin{array}{l}63 \\
40\end{array}$ & $\left.\begin{array}{l}\text { Miliary tuberculosis } \\
\text { Spastic diplegia }\end{array}\right\} \begin{array}{l}\text { Control } \\
\text { cases. }\end{array}$ \\
\hline $\begin{array}{l}\text { M. McM. } \\
\text { M. A. M. } \\
\text { J. G. } . \\
\text { C. B. . } \\
\text { M. McG. } \\
\text { J. B. } . \\
\text { R. McN. }\end{array}$ & $\begin{array}{l}33 \\
32 \\
11 \\
20 \\
13 \\
14 \\
31\end{array}$ & $\begin{array}{l}\frac{1}{2} \\
\frac{1}{2} \\
\frac{1}{2} \\
\frac{1}{2} \\
1 \\
1\end{array}$ & $\begin{array}{l}55 \\
35 \\
32 \\
57 \\
30 \\
27 \\
42\end{array}$ & $\begin{array}{r}66 \\
9 \\
190 \\
172 \\
130 \\
92 \\
35\end{array}$ & $\begin{array}{cc}\text { Tuberculous meningitis. } \\
\text {,, } \\
\text {," } \\
\text {, } & , \\
\text {," } & , \\
\text {," } & ,\end{array}$ \\
\hline
\end{tabular}

It would appear from these tests that there is no interference with the permeability of the blood-brain barrier to glucose. Further support to this view is afforded by the finding of normal values for non-protein nitrogen content of blood and cerebrospinal fluid in all forms of meningitis at all stages of the disease and by the fact that normal figures were obtained for the ratio of blood chloride to cerebrospinal fluid chloride in both purulent and tuberculous meningitis. The results for chloride estimations have already been reported (Hendry, 1939) and are in agreement with those of Linder and Carmichael (1928). 
Further evidence against diminished permeability of the choroid plexuses and in favour of glycolysis being the cause of reduction in the cerebrospinal fluid sugar content is afforded by a study of the lactic acid content of the blood and the cerebrospinal fluid. It is known that lactic acid is one stage in the breakdown of glucose to $\mathrm{CO}_{2}$ and $\mathrm{H}_{2} \mathrm{O}$, and if the lactic acid content of the spinal fluid can be shown to be increased above normal it is evidence that the glycolysis is taking place in the fluid. According to previous workers (tables 2 and 3), the normal ratio of cerebrospinal fluid lactic acid to blood lactic acid is 0.6 to 1.0 and the normal cerebrospinal fluid lactic acid content 6 to $30 \mathrm{mgm}$. per cent. In meningitis, on the other hand, it is generally agreed that there is no alteration in the blood lactic acid content, but that there is a considerable increase in the amount of the acid in the cerebrospinal fluid, indicating that glycolysis takes place there. Geldrich (1934) quotes 120 to $150 \mathrm{mgm}$. per cent. for his series of meningitis cases, and believes that any value over $40 \mathrm{mgm}$. per cent. should be regarded as pathological, whereas Kopetzy and Fishberg (1933) found the ratio of cerebrospinal fluid lactic acid to blood lactic acid ranged from $3 \cdot 0$ to $4 \cdot 0$.

TABLE 2

NORMAL CONTENT OF LACTIC ACID IN CEREBROSPINAL FLUID

\begin{tabular}{|c|c|c|c|}
\hline \multirow{2}{*}{\multicolumn{2}{|c|}{ OBSERVER }} & \multicolumn{2}{|c|}{ C.S.F. LACTIC ACID IN MGM. PER CENT. } \\
\hline & & MAXIMUM & MINIMUM \\
\hline 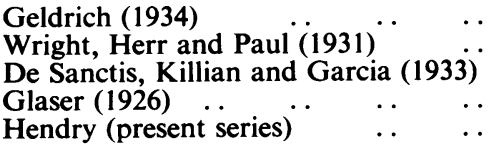 & $\begin{array}{l}\cdots \\
\cdots \\
\cdots \\
\cdots\end{array}$ & $\begin{array}{l}20 \\
30 \\
15 \\
27 \\
30\end{array}$ & $\begin{array}{r}10 \\
6 \\
8 \\
11 \\
7\end{array}$ \\
\hline
\end{tabular}

TABLE 3

NORMAL RATIO OF CEREBROSPINAL FLUID TO BLOOD LACTIC ACID

\begin{tabular}{|c|c|c|c|}
\hline OBSERVER & & MAXIMUM RATIO & MINIMUM RATIO \\
\hline $\begin{array}{l}\text { De Sanctis, Killian and Garcia (1933) } \\
\text { Wright, Herr and Paul (1931) } \\
\text { Kopetzy and Fishberg (1933) } \\
\text { Hendry (present series) }\end{array}$ & $\begin{array}{l}\ldots \\
\cdots \\
\cdots\end{array}$ & $\begin{array}{l}0.80 \\
0.80 \\
1.00 \\
1.00\end{array}$ & $\begin{array}{l}0.90 \\
\overline{0.60} \\
0.52\end{array}$ \\
\hline
\end{tabular}

In the present series whilst blood lactic acid readings were within normal limits, the cerebrospinal fluid lactic acid ranged from 25 to $200 \mathrm{mgm}$. per cent. and the ratio from $0 \cdot 8$ to $2 \cdot 3$. In meningococcal cases, as recovery took place and the sugar content of the cerebrospinal fluid rose, the lactic acid content fell, whilst in tuberculous meningitis as the condition worsened and the sugar content of the cerebrospinal fluid fell the lactic acid content rose. Fig. 1 and 2 demonstrate these findings in typical cases. 


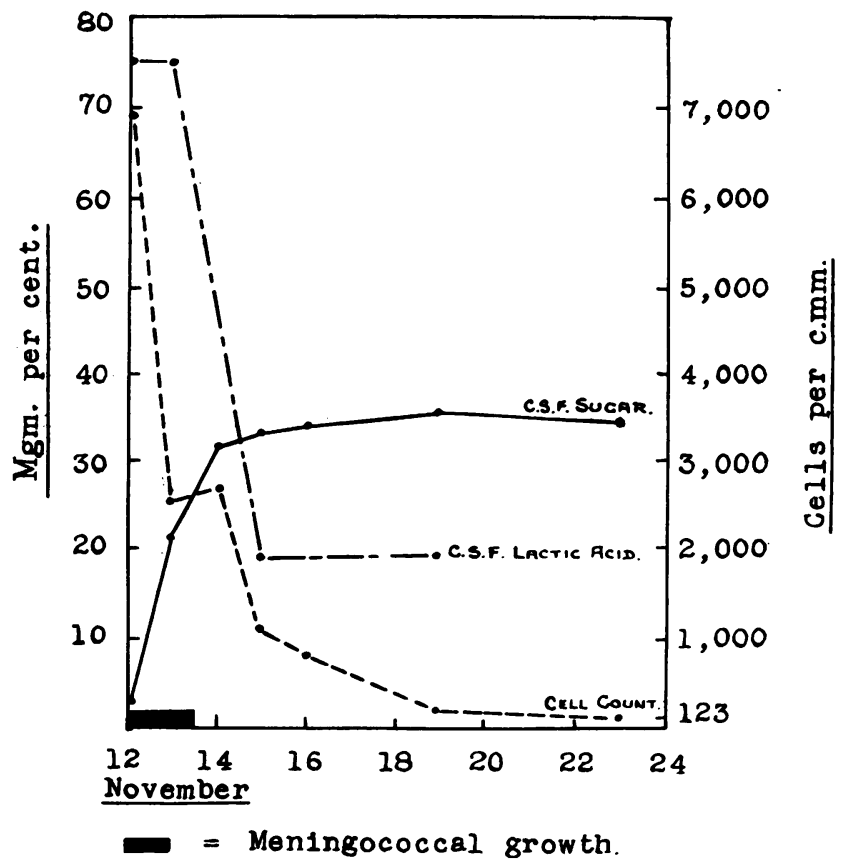

FIG. 1.-Changes in the sugar and lactic acid content and cell count of the cerebrospinal fluid in the course of meningococcal meningitis.

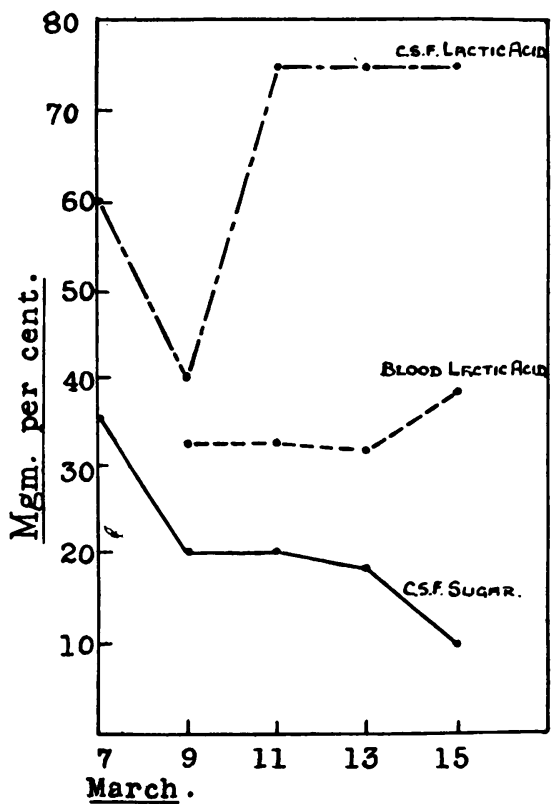

FIG. 2.-Changes in the sugar and lactic acid content of the cerebrospinal fluid and in the blood lactic acid content in tuberculous meningitis. 
2. Tests to determine if the presence of bacteria is the cause of the decrease in cerebrospinal fluid sugar content in meningitis.-Five c.c. of sterile cerebrospinal fluid were incubated with 0.01 c.c. of bacterial emulsion $(2,000,000,000$ organisms per c.c.). Fluid removed for the purpose of encephalography enabled sufficient to be available from a single patient to provide a control tube of fluid and five others to each of which was added one of five different strains of bacteria. The organisms selected for the test were meningococcus, pneumococcus, b. coli, staphylococcus albus and staphylococcus aureus. In table 4 the results are shown of sugar estimations in the control before incubation and in all six specimens twenty-four hours after incubation. From this it will be seen that $b$. coli proved to be actively glycolytic, whilst no glycolysis was brought about by the other four types of bacteria, any difference in the glucose content of the respective four fluids before and after incubation being well within the bounds of experimental error.

TABLE 4

TO SHOW THE EFFECT ON SUGAR CONTENT OF INCUBATING 5 C.C. OF NORMAL CEREBROSPINAL FLUID INOCULATED WITH 0.01 C.C. BACTERIAL EMULSION (2,000,000,000 BACTERIA PER C.C.) FOR TWENTY-FOUR HOURS

\begin{tabular}{c|c|c|c|c|c|c}
\hline $\begin{array}{c}\text { CONTROL C.S.F., } \\
\text { MGM. PER CENT. }\end{array}$ & \multicolumn{5}{|c|}{$\begin{array}{c}\text { INOCULATED C.S.F. AFTER 24 HOURS INCUBATION, } \\
\text { MGM. PER CENT. }\end{array}$} \\
\hline $\begin{array}{c}\text { BEFORE } \\
\text { INCUBATION }\end{array}$ & $\begin{array}{c}\text { AFTER } \\
\text { INCUBATION }\end{array}$ & $\begin{array}{c}\text { C.S.F. AND } \\
\text { STAPH. } \\
\text { ALBUS }\end{array}$ & $\begin{array}{c}\text { C.S.F. AND } \\
\text { STAPH. } \\
\text { AUREUS }\end{array}$ & $\begin{array}{c}\text { C.S.F. AND } \\
\text { MENINGO- } \\
\text { COCCI }\end{array}$ & $\begin{array}{c}\text { C.S.F. AND } \\
\text { PNEUMO- } \\
\text { COCCI }\end{array}$ & $\begin{array}{c}\text { C.S.F. AND } \\
\text { B. COLI }\end{array}$ \\
\hline 59.25 & 58.39 & 55.55 & 55.94 & 57.55 & 60.0 & Sugar absent \\
\hline
\end{tabular}

A similar test was carried out later with a human strain of $b$. tuberculosis. No glycolysis occurred after twenty-four hours' incubation, a finding in agreement with the work of Loebel, Shorr and Richardson (1933), who reported almost negligible breakdown of glucose to lactic acid by this organism.

3. Tests to determine if the presence of leucocytes causes reduction in the sugar content of the cerebrospinal fluid.-To a test-tube containing sterile normal cerebrospinal fluid, leucocytes obtained from the centrifuged sediment of citrated normal blood were added. A cell count was made and the fluid incubated at body temperature for twenty-four hours. A control specimen of the same cerebrospinal fluid to which leucocytes had not been added was incubated under the same conditions. Sugar estimations were made on the control specimen before incubation and on both specimens after incubation, when cultures were taken in order to exclude the possibility of glycolysis being due to bacterial contamination. In six experiments in which the resulting culture was sterile, a reduction was found in the amount of glucose in the cerebrospinal fluid to which white blood cells had been added, but none in the control specimen. The results are set out in table 5 , and it will be noted that the decrease in sugar content is roughly in proportion to the number of added cells, a finding 
which corresponds to those of Soedjono (1938). Table 6 shows a similar test in which lymphocytes were added to a cerebrospinal fluid one other specimen of which was treated as above with white blood cells and a third specimen used as a control. The lymphocytes were obtained from the centrifuged sediment of a specimen of pleural exudate the film of which showed 100 per cent. lymphocytes and the culture of which was sterile. As it so happened, the resulting cell counts were close for both lymphocytes and white blood cells. The reduction in sugar content in the fluid to which lymphocytes were added is almost negligible and within the $5 \mathrm{mgm}$. per cent. limit of experimental error, whilst the reduction in sugar when white blood cells were used is in keeping with the results of the other five tests.

TABLE 5

TO SHOW THE EFFECT ON SUGAR CONTENT OF ADDING WHITE BLOOD CELLS TO NORMAL CEREBROSPINAL FLUID-SUGAR ESTIMATIONS BEFORE AND AFTER INCUBATION

\begin{tabular}{|c|c|c|c|c|c|}
\hline \multirow{2}{*}{ CASE } & \multicolumn{2}{|c|}{ CONTROL C.S.F., MGM. PER CENT. } & \multirow{2}{*}{$\begin{array}{c}\text { C.S.F. AND } \\
\text { W.B.C. AFTER } \\
\text { INCUBATION, } \\
\text { MGM. PER CENT. }\end{array}$} & \multirow{2}{*}{$\begin{array}{l}\text { CELL COUNT, } \\
\text { PER C.MM. }\end{array}$} & \multirow{2}{*}{ CULTURES } \\
\hline & $\begin{array}{c}\text { BEFORE } \\
\text { INCUBATION }\end{array}$ & $\begin{array}{c}\text { AFTER } \\
\text { INCUBATION }\end{array}$ & & & \\
\hline $\begin{array}{l}1 \\
2 \\
3 \\
4 \\
5 \\
6\end{array}$ & $\begin{array}{c}72 \cdot 07 \\
70 \cdot 17 \\
50 \cdot 36 \\
100 \cdot 0 \\
51 \cdot 61 \\
87 \cdot 9\end{array}$ & $\begin{array}{c}72 \cdot 07 \\
66.09 \\
50 \cdot 36 \\
101 \cdot 6 \\
52 \cdot 20 \\
91 \cdot 0\end{array}$ & $\begin{array}{l}32 \cdot 0 \\
40 \cdot 0 \\
15 \cdot 27 \\
44 \cdot 44 \\
36 \cdot 54 \\
6 \cdot 29\end{array}$ & $\begin{array}{r}3,200 \\
2,400 \\
8,000 \\
16,000 \\
1,800 \\
10,800\end{array}$ & $\begin{array}{c}\text { Sterile } \\
\text { ”, } \\
\Longrightarrow \\
\Longrightarrow \\
\text { ”, }\end{array}$ \\
\hline
\end{tabular}

TABLE 6

TO SHOW THE EFFECT ON SUGAR CONTENT OF ADDING WHITE BLOOD CELLS AND LYMPHOCYTES TO NORMAL CEREBROSPINAL FLUID-SUGAR ESTIMATIONS BEFORE AND AFTER INCUBATION

\begin{tabular}{|c|c|c|c|}
\hline \multicolumn{2}{|c|}{ CONTROL C.S.F. MGM. PER CENT. } & \multirow{2}{*}{$\begin{array}{l}\text { C.S.F. AND W.B.C., } \\
2,400 \text { PER C.MM. } \\
\text { MGM. PER CENT. }\end{array}$} & \multirow{2}{*}{$\begin{array}{l}\text { C.S.F. AND LYMPHOCYTES, } \\
\text { 2,800 PER C.MM. } \\
\text { MGM. PER CENT. }\end{array}$} \\
\hline BEFORE INCUBATION & AFTER INCUBATION & & \\
\hline $64 \cdot 0$ & $64 \cdot 0$ & $29 \cdot 9$ & $59 \cdot 3$ \\
\hline
\end{tabular}

Cultures all sterile.

From these findings it may be concluded that white cells have a glycolytic action on the sugar of normal spinal fluid and that this is probably due to polymorphonuclear cells rather than to lymphocytes.

\section{Discussion}

The above findings suggest an explanation for the changes in the cerebrospinal fluid sugar content found in meningitis. In the early stages of cerebro- 
spinal fever a greatly increased cell count and a positive bacterial culture are almost invariably found. At this time the sugar content is extremely low. The present series of cases was treated with sulphanilamide, and it was customary to find a sterile cerebrospinal fluid on the second or at the latest on the third occasion on which lumbar puncture was performed. As at this stage of the illness the cell count is still high and the sugar content, though rising, well

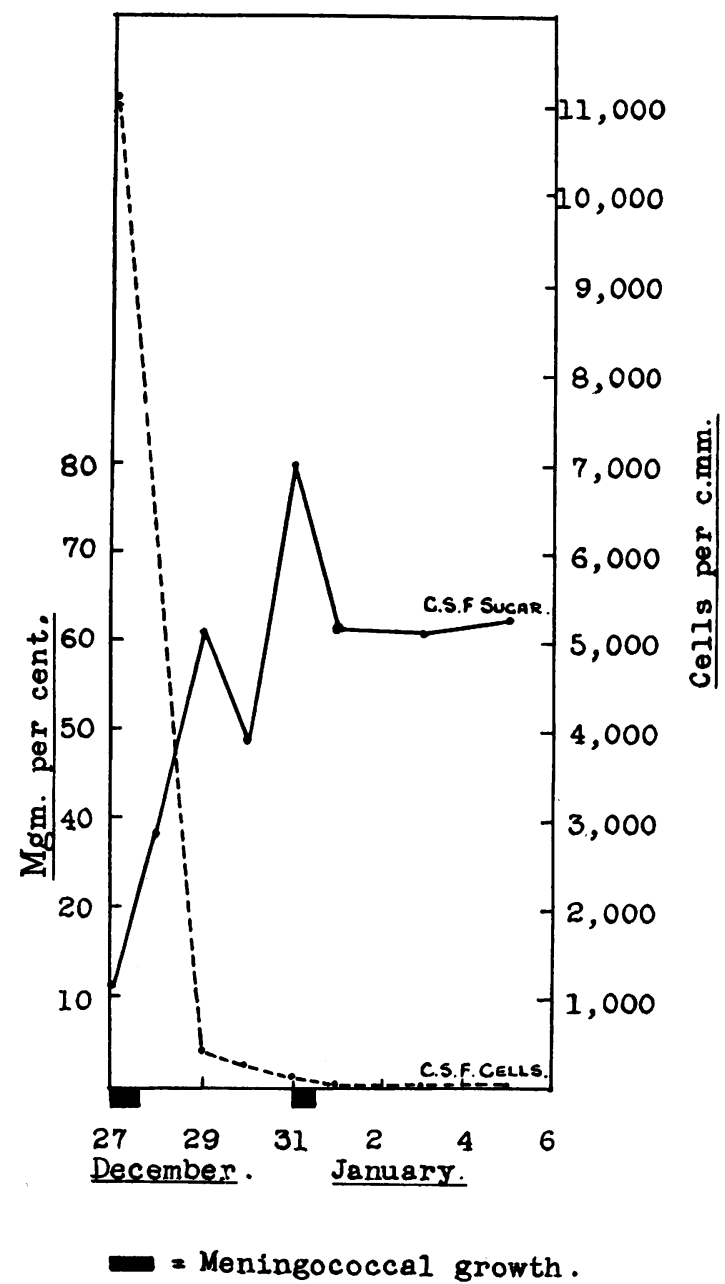

FIG. 3.-To show that the presence of meningococci in the cerebrospinal fluid does not influence its sugar content.

below normal limits, these findings would suggest that meningococci are not responsible for the breakdown of glucose. Fig. 3 shows the sugar and cell count changes in a typical case. It is interesting to note that, on the fourth day after the fluid had become sterile, there was a recurrence of a positive bacterial culture and that this had no effect on the sugar content, which, like the cell count, was returning to normal limits. 
An observation noted in these cases of meningococcal meningitis throws some light on the question whether polymorphonuclear cells or lymphocytes are responsible for the reduction in the cerebrospinal fluid sugar content. In the course of recovery the cell picture of the fluid changes from being almost entirely polymorphonuclear to being largely composed of lymphocytes. In the early stages there is great reduction in the cerebrospinal fluid sugar content, whilst in the later stages when the exudate is largely composed of lymphocytes the sugar content approaches the normal level. Further, in conditions such as benign lymphocytic meningitis, in which there is a purely lymphocytic exudate, there is no sugar reduction in the spinal fluid.

Two cases of meningitis due to b. coli showed complete absence of cerebrospinal fluid sugar, an occurrence which might be expected in view of the fact

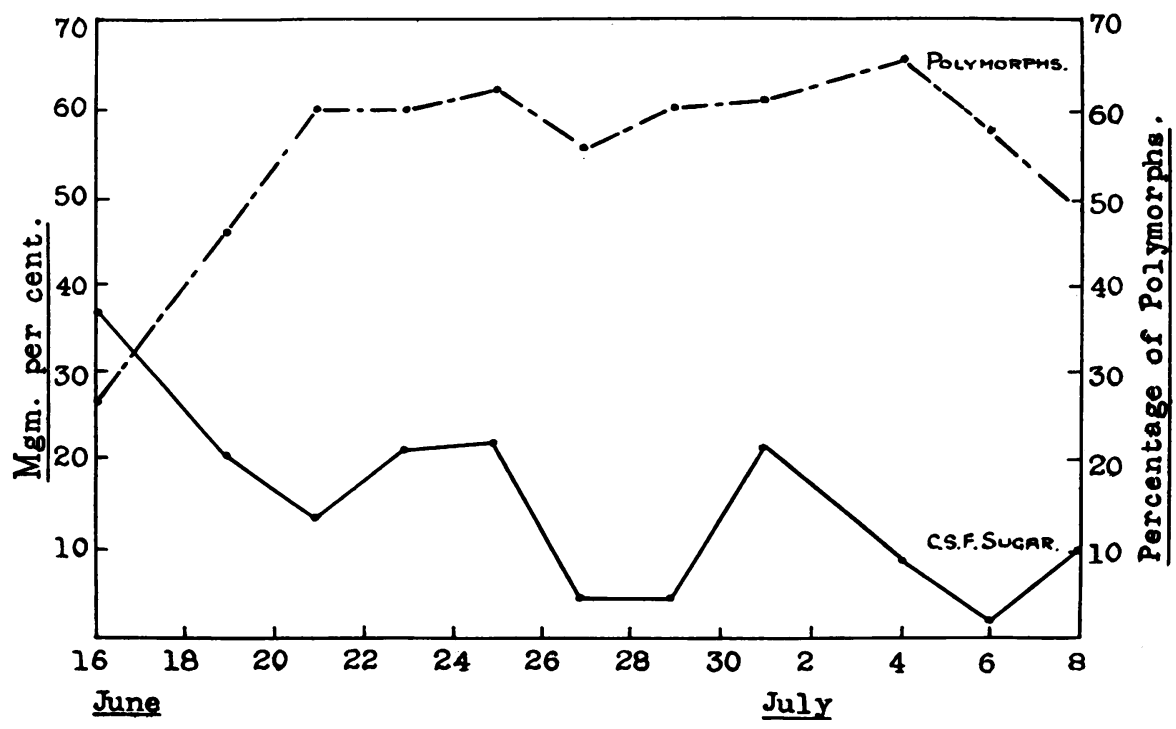

Fig. 4.-To show the effect on the sugar content of increase in the number of polymorphonuclear leucocytes in the cerebrospinal fluid in tuberculous meningitis.

that two factors are at work, a strongly glycolytic organism in addition to a large polymorphic cellular exudate.

From the findings in tuberculous meningitis, conclusions are not so easily drawn, but some suggestions may be put forward. As the tubercle bacillus has practically no power to break down sugar and as it is present in the cerebrospinal fluid only in small numbers, the part it plays in reduction of cerebrospinal fluid sugar may be neglected.

In the early stages of the disease the cellular exudate in the spinal fluid is largely lymphocytic and at this time the sugar content of the fluid is not greatly below normal. As the disease progresses to its fatal issue, there is an increase in the number of polymorphonuclear cells and a simultaneous decrease in the sugar content. Fig. 4 shows the proportion of polymorphonuclear cells to lymphocytes and the spinal fluid sugar content in a case of 
tuberculous meningitis observed from its early stages till death. It demonstrates the fall in the glucose content as the number of polymorphonuclear cells increases.

\section{Conclusions}

1. The permeability of the choroid plexus to glucose is not affected in cases of meningitis.

2. Reduction in cerebrospinal fluid sugar in meningitis is due to glycolysis within the cerebrospinal system.

3. The presence of the meningococcus or tubercle bacillus in the spinal fluid is not responsible for the reduction in its sugar content in meningitis due to these organisms. B. coli has a glycolytic action and in coliform meningitis the reduction in cerebrospinal fluid sugar is in great part due to this.

4. Polymorphonuclear leucocytes possess powers of glycolysis and their presence is the reason for reduction in cerebrospinal fluid sugar in purulent meningitis and for the progressive decrease in its sugar content in tuberculous meningitis.

Thanks are due to Professor G. B. Fleming and other members of the clinical staff for advice and help and to the members of the bacteriological and biochemical laboratories for technical assistance.

This work was carried out during the tenure of a Muirhead Scholarship and part of the expenses were defrayed by the Medical Research Council.

\section{REFERENCES}

Barron, E. S. G., and Harrop, G. A. (1929). J. biol. Chem., 84, 89.

Chevassut, K. (1927). Quart. J. Med., 21, 796.

Dandy, W. E. (1919). Ann. Surg., 70, 129.

De Sanctis, A. G., Killian, J. A., and Garcia, T. (1933). Amer. J. Dis. Child., 46, 239.

Fasold, H., and Schmidt, H. A. (1929). Klin. Wschr., 8, 1532.

Folin, O., and Wu, H. (1920). J. biol. Chem., 41, 367.

Geldrich, J. (1934). Arch. Kinderheilk., 101, 108.

Glaser, J. (1926). J. biol. Chem., 69, 539.

Hendry, E. (1939). Arch. Dis. Childh., 14, 159.

Kopetzy, S. J. (1933). Quoted in J. Lab. clin. Med., 18, 796.

- - and Fishberg, E. H. (1933). Ibid.

Levene, P. A., and Meyer, G. (1912). J. biol. Chem., 11, 361.

Linder, G. G., and Carmichael, E. A. (1928). Biochem. J., 22, 46.

Loebel, R. O., Shorr, E., and Richardson, H. B. (1933). J. Bact., 26, 167.

McLeod, J. J. R. (1921). Physiol. Rev., 1, 208.

Rimele, B. (1938). Arch. Kinderheilk., 113, 223.

Soedjono, D. P. (1938). Maandschr. Kindergeneesk., 7, 337.

Tcherkassov, A. V., and Jolkver, E. E. (1935). Rev. franç. Pédiat., 11, 350.

Walter, F. K. (1929). Die Blutliquorschranke, Leipzig.

Weed, L. H. (1914-15). J. med. Res., 31, 21, 51, 93.

Weichsel, M., and Herzger, G. (1936). J. Pédiat., 9, 763.

Wright, S., Herr, E. S., and Paul, J. R. (1931). J. clin. Invest., 9, 443. 